\title{
Designing of Fabric Reinforced Polymer in the Assessment of Sorption Capacity of Mussel Shell Powder for Divalent lon: GIS Mapping and Statistical Studies
}

\section{S. Charulatha}

PSGR Krishnammal College for Women

K.S. Thangamani

Dr. N.G.P. Institute of Technology https://orcid.org/0000-0003-3340-4813

N. Muthulaksmi Andal ( $\square$ thangs2012@gmail.com )

PSGR Krishnammal College for Women

\section{Research Article}

Keywords: Adsorption, Zinc ions, Parameters, Mussel shell powder, Isotherms, Column Studies, Effluent Treatment

Posted Date: November 17th, 2021

DOI: https://doi.org/10.21203/rs.3.rs-1070934/v1

License: (c) (1) This work is licensed under a Creative Commons Attribution 4.0 International License.

Read Full License 


\title{
Designing of Fabric Reinforced Polymer in the Assessment of Sorption Capacity of Mussel Shell Powder for Divalent Ion: GIS Mapping and Statistical Studies
}

\author{
S.Charulatha $^{\mathrm{a}}$, K.S. Thangamani ${ }^{\mathrm{b}}$, N.Muthulaksmi Andal ${ }^{\mathrm{a}^{*}}$ \\ ${ }^{a}$ Department of Chemistry, PSGR Krishnammal College for Women, Coimbatore-4 \\ ${ }^{b}$ Department of Chemistry, Dr. N.G.P. Institute of Technology, Coimbatore-641048
}

\begin{abstract}
This paper discusses the efficiency of acid modified mollusc shell powder in adsorbing $\mathrm{Zn}$ (II) ions from synthetic wastewater and actual wastewater samples discharged from electroplating industries. The chemically treated adsorbent was characterized in terms of structure and surface properties. The parameters such as, size of the sorbent particles, dosage, initial $\mathrm{Zn}(\mathrm{II})$ concentration, temperature, contact time $\mathrm{pH}$ and temperature were varied for optimization using batch studies. The adsorbate-adsorbent system was studied by Langmuir, Freundlich, Tempkin and DKR isotherms. The adsorption experiments were conducted in a column packed with the acid modified mollusc shell powder. Further, real wastewater samples having $\mathrm{Zn}$ (II) concentration higher than the permissible levels were collected from the industrial belt in Coimbatore, to assess the potential of the bio adsorbent. A fiber reinforced polymer fabricated with the adsorbent material installed at the effluent discharge plants achieved $100 \%$ $\mathrm{Zn}$ (II) removal from electroplating wastewaters. Statistical analysis performed using SPSS software showed significant correlation among the input parameters and the analytical results post-adsorption.
\end{abstract}

Keywords: Adsorption, Zinc ions, Parameters, Mussel shell powder, Isotherms, Column Studies, Effluent Treatment

\section{Introduction}

Industrial effluents generated from various industries viz., mining, metallurgy, plating, paints, pigments etc., are the main sources of heavy metal pollution. Environmental Protection Agency (EPA) proposed that over exposure to $\mathrm{Zn}^{2+}$ ions leads to many undesirable physiological conditions such as hyperosmolarity, hyponatremia, stomach ache, vomiting sensation, light headedness and ataxia [1]. Thus, removal of zinc ions is essential to address the consequences of 
pollution. Although there are a range of adsorption techniques, adsorption is one of the best and effective processes for the treatment of effluents because it minimizes the sludge formation, and is cost effective [2,3]. Many adsorbent materials of plant and animal origin proved effective for the removal of various metal ions [4-9]. These natural materials are readily available, cheap and easily modifiable to suit the needs. In this context, this work investigates the efficiency of chemically treated mussel shell powder in the adsorption of $\mathrm{Zn}(\mathrm{II})$ ions from aqueous solutions. Mussel shell belongs to the family bivalve molluscs found in saltwater and freshwater habitats. They are discarded as waste from shellfish processing.

\section{Materials and Methods}

\subsection{Chemicals}

Stock solution of $1000 \mathrm{mg} / \mathrm{L}$ zinc nitrate was prepared by dissolving appropriate quantity of the zinc salt in water. Aliquots of the adsorbate solutions of varying $\mathrm{Zn}$ (II) ion concentrations (100-1000 mg/L: $100 \mathrm{mg} / \mathrm{L}$ ) were prepared by progressive dilutions from the stock solution, at natural $\mathrm{pH}$ conditions.

\subsection{Preparation/Treatment of Adsorbent Materials}

Mollusc shells were collected from shellfish processing units. The shells were cleansed using double distilled (DD) water repeatedly and converted into a coarse pow der using a mortar and pestle. Then, the coarse mollusc shell powder (MSP) was kept in a flat bottom flask containing decinormal hydrochloric acid for 4 hours. Following this chemical treatment, MSP was washed with DD water again and dried under direct sunlight. This treated powder will be mentioned as TMSP hereafter. The TMSP was crushed well to a fine dust using a laboratory blender and segre gated based on the particle size as 85 BSS, 72 BSS, 52 BSS, 36BSS and 22 BSS. These adsorbent samples were stocked in sealed holders. The images of the untreated mollusc shell pow der and TMSP (0.18 mm: optimized partic le size) are shown in Fig 1a\& 1b

Treated mussel shell powder samples of different mesh sizes (15 samples) were microscoped under a CX21i Binocular Microscope to determine the particle size. The dimensions of each sample were measured and averaged. Finally, the particle size was calculated using multiplication factors. The calculated particle sizes for the mesh sizes 85BSS, 72BSS, 52BSS, 36BSS and 22BSS are $0.18 \mathrm{~mm}, 0.21 \mathrm{~mm}, 0.30 \mathrm{~mm}, 0.42 \mathrm{~mm}$ and $0.71 \mathrm{~mm}$, respectively. 


\subsection{Surface Characterization}

A JEOL JFM-6390 Scanning Electron Microscope with EDX was used to study the surface structure of the treated mollusc shell powder. Similarly, a Micromeritics (BEL, Japan Inc.) Surface Area Analyzer was employed to determine the surface area and pore volume by $\mathrm{N}_{2}$ adsorption at $77 \mathrm{~K}$ following BET method.

Evaluation of the particle/ mesopore size distribution of sorbent material was carried out by BET (Fig.2a) and BJH (Fig.2b) methods. The adsorption performance is highly dependent on the internal pore structure. Pore sizes are classified in accordance with the classification adopted by the International Union of Pure and Applied Chemistry (IUPAC manual., 1982) i.e; micropores $(\mathrm{d}<20 \AA)$, mesopores $(20 \AA<\mathrm{d}<500 \AA)$ and macropores $(\mathrm{d}>500$ $\AA$ ]. Because of the larger sizes of the liquid molecules, the adsorbents for liquid phase adsorbates should possess predominantly mesopores in the structure[10].The mesopores are responsible for

the better surface area of TMSP $\left(1.52 \mathrm{~m}^{2} / \mathrm{g}\right)$, possible through the activation process. The mean pore diameter value as inferred from BET plot is found to be $24.04 \mathrm{~nm}$. Particles under study are found to possess mesoporous nature predominantly, as their pore diameter lie in the range of 20 $\AA<\mathrm{d}<500 \AA$

\subsection{Batch Mode Adsorption Studies}

In the batch adsorption studies, the $\mathrm{Zn}$ (II) samples were shaken well with TMSP in a KEMI agitator. To optimize the system for maximal adsorption, the particle size of TMSP $(0.71$ $\mathrm{mm}, 0.42 \mathrm{~mm}, 0.30 \mathrm{~mm}, 0.21 \mathrm{~mm}$ and $0.18 \mathrm{~mm}$ ), dosage (200-500 mg $100 \mathrm{mg}$ interval), preadsorption concentration of $\mathrm{Zn}$ (II) solution (100-1000 ppm; $100 \mathrm{ppm}$ interval), contact time (30 min, $60 \mathrm{~min}, 120 \mathrm{~min}), \mathrm{pH}(3,5,7,9$ and 11)and temperature $(293 \mathrm{~K}-333 \mathrm{~K}: 10 \mathrm{~K}$ intervals ) were varied.

The pre- and post-adsorption $\mathrm{Zn}(\mathrm{II})$ concentrations were determined using a Shimadzu (AA 6200) atomic absorption spectrophotometer.

\subsubsection{Data Evaluation}

The percentage of adsorption of $\mathrm{Zn}(\mathrm{II})$ ions from the test solutions was calculated by equation (1) [11] 


$$
\% \text { removal }=\frac{C_{0}-C}{C_{0}} \times 100
$$

Similarly, application of equation (2) gives the quantity of $\mathrm{Zn}(\mathrm{II})$ ions removed by the $\operatorname{adsorbent}(q)$.

$$
\mathrm{q}=\frac{V\left(C_{0}-C\right)}{W}
$$

where $\mathrm{V}, \mathrm{W}, \mathrm{C}_{i}$ and $\mathrm{C}_{e}$ are, respectively, volume of the solution in $\mathrm{L}$, mass of the adsorbent in $\mathrm{g}$, initial and equilibrium metal concentrations $(\mathrm{mg} / \mathrm{L})$.

\subsection{Statis tical Analysis}

All statistical analyses were carried out with the help of IBM SPSS (Statistical Product and Service Solutions) package version 20 using ANOVA at 95\% confidence level. Pearson Product-Moment Correlation Coefficient Method was used to establish the relationship between the amount of adsorbed $\mathrm{Zn}(\mathrm{II})$ ions and the variables.

\section{Results and Discussion}

\subsection{SEM Analysis}

Figures $3 \mathrm{a}$ and $3 \mathrm{~b}$ show the surface structures TMSP before and after adsorption of $\mathrm{Zn}(\mathrm{II})$ ions. From Fig 3a, it is evident that the surface of the bare TMSP is porous and rough. But, the image after $\mathrm{Zn}$ (II) adsorption reveals a smooth surface (Fig 3a). From, these two figures, the adsorption of $\mathrm{Zn}$ (II) ions onto the active sites of the surface of TMSP can be confirmed.

\subsection{EDAX Analysis}

The chemical compositions of the adsorbent material before and after adsorption were determined by EDAX spectroscopy. Figures $4 \mathrm{a}$ and $4 \mathrm{~b}$, respectively, show the EDAX spectrum of free TMSP and Zn(II)-loaded TMSP. The EDAX spectrum of TMSP showed that oxygen, carbon, calcium and chlorine are the major elements [12]. In the spectrum of $\mathrm{Zn}$ (II)-loaded TMSP, a new peak observed at the energy range 8-10 KeV (fig 4b) confirms the adsorption of $\mathrm{Zn}$ (II) ions onto TMSP. 


\subsection{FTIR Spectral Studies}

FTIR spectra of unloaded and Zn(II) loaded TMSP is shown in Fig. 5 . The broad intense peak at $3722 \mathrm{~cm}^{-1}$ indicative of the stretching of O-H group [13] The peak at $1465 \mathrm{~cm}^{-1}$ corresponds to carboxylate groups. The $856 \mathrm{~cm}^{-1}$ peak relates to the presence of aromatic heterocyclic molecules. Inclines and declines in the intensities of the peaks as perceived from the figure, indicate the appropriate shifts that had occurred in the FTIR spectra of $\mathrm{Zn}$ (II) laden material.

\subsection{Effect of Particle sizes}

The change in adsorption behavior of the Zn(II)-TMSP system with different particle size of the adsorbent $(0.18 \mathrm{~mm}, 0.32 \mathrm{~mm}, 0.41 \mathrm{~mm}$ and $0.71 \mathrm{~mm})$ was experimentally verified and illustrated in the bar diagram (Fig 6). The adsorption of $\mathrm{Zn}$ (II) onto TMSP was observed to increase from $19.32 \mathrm{mg} / \mathrm{g}$ to $83.76 \mathrm{mg} / \mathrm{g}$, as the particle size decreased from $0.71 \mathrm{~mm}$ to $0.18 \mathrm{~mm}$ as expected based on the relationship between adsorption and surface area. Thus, $0.18 \mathrm{~mm}$ was fixed as the optimum particle size for further experiments. As per the statistical tool analysis (Table 1), the $\mathrm{P}$-value $(0.0297)$ at $95 \%$ confident level $(\mathrm{P}<0.05)$ confirms that there is a significant correlation $(r=-7395)$ between the particle size of the adsorbent and the amount of solute adsorbed.

\subsection{Effect of Dosage}

Bar chart (Fig 7) depicts the adsorption efficiency of TMSP with dosages. The maximum $\mathrm{Zn}$ (II) absorption at $1000 \mathrm{mg}$ TMSP is due to the increased surface area. The P-value (0.0005) at 95\% confident level $(\mathrm{P}<0.05)$ shows positive correlation $(\mathrm{r}=0.9942)$ between adsorbent dosage and the amount of $\mathrm{Zn}(\mathrm{II})$ adsorbed.

\subsection{Effect of Initial Concentration and Agitation Time}

The influence of contact time on $\mathrm{Zn}$ (II) removal is shown in the bar diagram (Fig. 8 ). The amount of $\mathrm{Zn}$ (II) ion adsorbed by TMSP for different values of initial $\mathrm{Zn}$ (II) concentrations (100-1000ppm: 100ppm intervals) at room temperature can be noted from it. It is evident that as the initial $\mathrm{Zn}$ (II) concentration increases, the corresponding amount of absorption also increases from $58.81 \mathrm{mg} / \mathrm{g}$ to $83.76 \mathrm{mg} / \mathrm{g}$ at the contact time of 60 minutes. A further increase in the 
contact time has a negligible effect on the rate of adsorption. The reduction in the rate of adsorption at increased contact time may be due to the slow pore diffusion of the solute ion into the bulk of the adsorbent [14].

\subsection{Effect of $\mathrm{pH}$}

The role of $\mathrm{pH}$ has also been ascertained experimentally and shown in Fig.9. The amounts of $\mathrm{Zn}(\mathrm{II})$ removed (particle size and dose: $0.18 \mathrm{~mm} \mathrm{\&} 1000 \mathrm{mg}$ ) at different $\mathrm{pH}$ environments imply that a moderate acidic $\mathrm{pH}$ of 5.5 facilitate maximum adsorption. Highly acidic and alkaline $\mathrm{pH}$ actually hinders the removal of $\mathrm{Zn}$ (II) because of the interferences of $\mathrm{H}^{+}$ and $\mathrm{OH}^{-}$ions with the surface prior to adsorption, which decreases the number of active sites[15]. The calculated $\mathrm{P}$-value $(0.0455)$ at $95 \%$ confidence level $(\mathrm{P}<0.05)$, as evident from Table 2 proves the existence of significant correlation between $\mathrm{pH}$ and the amount of $\mathrm{Zn}$ (II) adsorption.

\subsection{Effect of Tempe rature}

Temperature has a pronounced effect on the adsorption capacity of the adsorbents. The effect of temperature (293-333 K: $10 \mathrm{~K}$ intervals) on $\mathrm{Zn}(\mathrm{II})$ are illustrated in table 1, where the adsorption percentage was observed to increase from 67.30 to 96.00 for $\mathrm{r}$ ise in temperatures $[16,17]$. The enhancement of adsorption capacity with temperature may be attributed to the increase in the mobility of ions, which can cause small pores to widen and provide more surfaces for adsorption $[18,19]$.

\subsection{Statistical Analysis}

Statistically significant corre lation between the experimental variables and the quantity of $\mathrm{Zn}(\mathrm{II})$ ions adsorbed onto the surface of TMSP was established by Pearson correlation analysis. These findings indicate that heavy metal pollution can be handled practicably once the factors affecting the adsorption of such ions are fixed. The Pearson correlation parameters are given in Table 3.

\subsection{Adsorption Isotherm Models}

Adsorption is otherms state the surface properties and affinity of the adsorbent towards the adsorbate [20]. Thus, different adsorption is otherms were applied to the $\mathrm{Zn}(\mathrm{II})$-TMSP system under the influence of varying initial concentrations using the experimental data to understand 
the process. Carrying out a linear regression and validation by correlation coefficients $\left(\mathrm{R}^{2}\right)$ can authenticate the best fit between the data and type of adsorption is otherm [21].

\subsubsection{Langmuir}

The Langmuir model assumes the occurrence of [22] sorption at precise homogeneous active sites that can attract only a single molecule. A second layer of adsorption is excluded in Langmuir isotherm and thus only a monolayer adsorption is possible, which is expressed by the following equation [23]

$$
\frac{\mathrm{C}_{\mathrm{e}}}{\mathrm{q}_{\mathrm{e}}}=\frac{\mathrm{C}_{\mathrm{e}}}{\mathrm{q}_{\mathrm{m}}}+\frac{1}{\mathrm{bq}_{\mathrm{m}}}
$$

where

$\mathrm{q}_{\mathrm{e}}=$ Sorption capacity of the sorbent $(\mathrm{mg} / \mathrm{g})$

$\mathrm{C}_{\mathrm{e}}=$ Equilibrium metal ion concentration in solution $(\mathrm{mg} / \mathrm{L})$,

$\mathrm{q}_{\mathrm{m}}=$ Maximum monolayer adsorption capacity of the sorbent $(\mathrm{mg} / \mathrm{g})$

$\mathrm{b}=$ Langmuir sorption constant (mg/L) related to the free energy of sorption.

The Langmuir constants $\mathrm{q}_{\mathrm{m}}$ and $\mathrm{b}$ were determined from the slope and intercept values of the linear plot of $\mathrm{C}_{\mathrm{e}} / \mathrm{q}_{\mathrm{e}}$ versus $\mathrm{C}_{\mathrm{e}}$ (Fig 10). Higher the value of $\mathrm{b}$, greater is the affinity of the adsorbent towards the metal ion [24]. The $R^{2}$ values $\left(R^{2}=0.9919\right)$ suggests maximum linearity and best fit of the isotherm for $\mathrm{Zn}(\mathrm{II})$-TMSP system.

\subsubsection{Freundlich}

In general, the adsorption characteristics of an aqueous can be studied by applying Freundlich isotherm. Batch isothermal data fitted to the linear form of the Freundlich isotherm equation,

$\log \mathrm{q}_{\mathrm{e}}=\log \mathrm{k}+1 / \mathrm{n} \log \mathrm{C}_{\mathrm{e}}$

where

$\mathrm{q}_{\mathrm{e}}=$ amount of metal ions sorbed per unit weight of the sorbent $(\mathrm{mg} / \mathrm{g})$

$\mathrm{C}_{\mathrm{e}}=$ equilibrium metal ion concentration $(\mathrm{mg} / \mathrm{L})$ of the metal ions in the solution

$\mathrm{K}_{\mathrm{f} \text { and }} 1 / \mathrm{n}$ are Freundlich constants related to adsorption capacity and adsorption intensity, respectively [25]. From the slope and intercept of the plot $\log \mathrm{q}_{\mathrm{e}} v s \log \mathrm{C}_{\mathrm{e}}$ (Fig. 11), values of $\mathrm{K}_{\mathrm{f}}$ 
and $\mathrm{R}^{2}$ were determined (Table 4). The constants and the correlation coefficient values imply that the system does not comply well with Freundlich isotherm $\left(\mathrm{R}^{2}=0.9765\right)$ compared to its compliance with Langmuir is otherm $\left(\mathrm{R}^{2}=0.9919\right)$.

\subsubsection{Tempkin Isotherm Model}

Tempkin is otherm was applied to the adsorption data under investigation, as per equation (17). Tempkin constants $A_{T}$ and $b_{T}$ which are related to the equilibrium binding constant and heat of adsorption are obtained from the linear plot of $\ln \mathrm{C}_{\mathrm{e}} \mathrm{vs} \mathrm{q}_{\mathrm{e}}$ (Fig. 12). The constants and the correlation coefficient values reported in table 4, indicate that the isotherm is obeyed by the systems effectively. Similar results were documented by earlier researchers [26, 27].

\subsubsection{Dubinin-Kaganer-Radushkevich Isotherm Model}

The equilibrium data were applied to the DKR isotherm model to determine the nature of sorption processes as physical or chemical. Fig. 13 represents the DKR plot for $\mathrm{Zn}$ (II) system. The value of correlation coefficient shown in table 4 , indicate that the DKR isotherm fitted well with the experimental data. The results show that the sorption of the metal ion onto the sorbent material may be carried out via chemical ion exchange mechanism, as their value lie above $8 \mathrm{~kJ} / \mathrm{mol}$. Similar results were reported for various other adsorbents [28, 29].

\subsection{Adsorption Dynamics}

The thermodynamic parameters such as change in free energy $\left(\Delta \mathrm{G}^{0}\right)$, enthalpy $\left(\Delta \mathrm{H}^{0}\right)$ and entropy $\left(\Delta \mathrm{S}^{0}\right)$ were calculated. The $\Delta \mathrm{H}^{0}, \Delta \mathrm{S}^{0}$ calculated from the slope and intercept of Vant Hoff plot (Fig. 14) are shown in table 5. The positive values of $\Delta \mathrm{H}^{0}$ indicate the presence of an energy barrier in the adsorption process which is endothermic in nature 215 . The negative values of $\Delta \mathrm{G}^{0}$ indicate the feasibility and spontaneous nature of adsorption of metal ions by the adsorbent [30]. The magnitude of $\Delta \mathrm{G}^{0}$ increased with temperature indicating that the sorption was more favourable at higher temperature [31]. The positive values of $\Delta S^{0}$ suggest that the increased randomness at the solid-solution interface during the 
adsorption of metal ions in aqueous solutions onto adsorbents [32]. The low value of $\Delta \mathrm{S}^{0}$ may imply that no remarkable change in entropy occurred during the sorption of metals on the adsorbent [33]. Similar trend was observed for adsorbents such as rice bran [34], tree fern [35], and rubber wood sawdust [36].

\subsection{Column Method}

The results obtained from the batch mode suggest the suitability and efficiency of TMSP in removing $\mathrm{Zn}(\mathrm{II})$ ions. Motivated by the batch mode results, the process was validated for quantification by continuous column runs. The inlet $\mathrm{Zn}$ (II) solutions of $1000 \mathrm{mg} / \mathrm{L}$ concentration was passed through the column packed with $300 \mathrm{~g}$ of $0.18 \mathrm{~mm}$ particle size of TMSP and the outlet solution was collected at the rate of $100 \mathrm{~mL} / 2 \mathrm{~min}$. The maximum sorption capacity after quantification led to the extension of treating real run-off samples from electroplating industries containing excess $\mathrm{Zn}(\mathrm{II})$ concentration.

\subsubsection{Column Packing}

A glass column (inner diameter $=2.5 \mathrm{~cm}$; height $=30 \mathrm{~cm}$ ), shown in Fig. 15 was first packed with glass wool (thickness $=3 \mathrm{~cm}$ ) followed by glass beads (thickness $=2 \mathrm{~cm}$ ). After making these two layers were made firm, about $50 \mathrm{~g}$ of the adsorbent (height $=6 \mathrm{~cm}$ ) was carefully placed over the glass bead layer. Finally, the adsorbent was covered with another layer of glass wool (thickness $=1 \mathrm{~cm})$.

About $500 \mathrm{~mL}$ of $1000 \mathrm{mg} / \mathrm{L} \mathrm{Zn(II)} \mathrm{solution} \mathrm{was} \mathrm{introduced} \mathrm{from} \mathrm{the} \mathrm{top} \mathrm{of} \mathrm{the} \mathrm{column}$ and the outlet sample was collected at a rate of $100 \mathrm{~mL} / 20 \mathrm{~s}$. After the collection of 1 litre of residual $\mathrm{Zn}(\mathrm{II})$ solution, $100 \% \mathrm{Zn}(\mathrm{II})$ removal was ensured. A gradual decline in percentage removal was observed upto $90 \%$ at the end of passing 15 litres of inlet $\mathrm{Zn}$ (II) solution. Further reduction was continued upto 20 litres of inlet solution, following that TMSP packed column exhausted. Pictorial representation of the packed column with the experimental solution is shown in Fig 15.

\subsection{Desorption/Regene ration Studies}

Double distilled water was run through the exhausted column followed by the addition of $0.01 \mathrm{M} \mathrm{H}_{2} \mathrm{SO}_{4}$ as eluent at a collection of $100 \mathrm{~mL} / 15 \mathrm{~min}$. A complete $\mathrm{Zn}$ (II) desorption was 
ensured through periodic analysis of the eluted samples through exhausted medium. After desorption, the packed material was again run with DD water. The regeneration capacity was registered as $90 \%$ recovery of TMSP against the freshly packed TMSP.

\subsection{Mapping of Industrial Area-Choice of Study}

Many electroplating industries were developed in Coimbatore. The electroplating units located at Kurumbapalayam area (highlighted in Table 6) were selected for the present study as numerous residential colonies nearby were subjected to heavy metal pollution due to improper and non-operative effluent treatment plants. Geographic Information System Mapping (GIS) of Sarcar Sama Kulam (study area) mapped using QGIS 3.8 software is shown in Fig 16, where in, the green shade indicates the CODEA Industrial Park (10.5 acre) near Saravanampatti which comprises of 22 units of electroplating industries.

\subsection{Collection of Effluents}

Wastewaters containing excess $\mathrm{Zn}$ (II) than the permissible levels were collected from various electroplating industries in Kurumbapalayam region. About $10 \mathrm{~L}$ of these effluent samples were collected in precleaned PET bottles of $1 \mathrm{~L}$ capacity from each industrial unit. Analys is of $\mathrm{Zn}(\mathrm{II})$ ion (AAS) after a series of dilutions from table 7 revealed the ir concentrations to exceed the permissible limits $(5.0 \mathrm{mg} / \mathrm{L})$. The recorded $\mathrm{pH}$ and conductivity values imply that the samples are acidic.

\subsubsection{Analysis of Industrial Effluents - Batch/Column Methods}

Although, all the samples had excess $\mathrm{Zn}$ (II) concentration, batch/column experiment setup was limited to the sample collected from electroplating unit VII. The sample was diluted to $50 \%$ and experimentally verified under optimized conditions. About $70 \%$ and $90 \%$ removal were achieved in batch and column studies, respectively.

\subsection{Designing and Installation- Fiber Reinforced Polymer Column}

Fiber Reinforced Polymer (FRP) Column was fabricated and installed at Kurumbapalayam, Coimbatore, Tamil Nadu with the assistance of a Design Engineer, Zion Enviro Systems Pvt. Ltd., Chennai. The dimensional and TMSP packing are shown below 
The pictures representing the FRP Column, packing of material, installation and operation at field level is shown in Fig. 17

The performance of the installed FRP Column was assessed by the passage of effluent sample $[\mathrm{Zn}(\mathrm{II})]$ through column inlet at a flow rate of $100 \mathrm{~mL} / 5 \mathrm{~min}$. About $15 \mathrm{~L}$ of the effluent sample was collected through the outlet and their residual concentrations were analyzed. The efficiency of the column was outstanding $(0.5 \mathrm{mg} / \mathrm{L}$ of residual $\mathrm{Zn}(\mathrm{II})$ against $40 \mathrm{mg} / \mathrm{L}$ initial concentration).

\section{Conclusion}

Mollusc shell powder treated with HCl (TMSP) was found to be a cheap and efficient adsorbent of $\mathrm{Zn}$ (II) ions from aqueous solutions. The unloaded and $\mathrm{Zn}$ (II)-loaded TMSP samples were characterized structurally and morphologically by various characterization techniques. The surface analysis of $\mathrm{Zn}(\mathrm{II})$-TMSP showed notable changes in the surface properties. The parameters such as, particle size of the adsorbent, dosage, initial concentration of $\mathrm{Zn}$ (II) ions, contact time, $\mathrm{pH}$ and temperature were optimized for maximal $\mathrm{Zn}(\mathrm{II})$ removal by batch studies. The experimental data when studied with Langmuir, Freundlich, Tempkin and DKR isotherm models to understand the type of adsorption, showed the best fit for Langmuir isotherm. The adsorption capacity of TMSP was also confirmed with column studies. Then, effluent wastewaters with higher $\mathrm{Zn}(\mathrm{II})$ concentration than the permissible levels were collected from Kurumbapalayam area and subjected to batch/column experiments. As close as $100 \%$ of $\mathrm{Zn}$ (II) removal from effluent wastewaters recorded in column studies against the batch studies (70\%) under similar conditions. The exhausted TMSP material of the column could be desorbed using $0.01 \mathrm{M} \mathrm{H}_{2} \mathrm{SO}_{4}$. Based on the column results and optimized conditions observed both at the laboratory and field levels for effluent analysis, a Fibre Reinforced Polymer (FRP) column was fabricated and installed at Kurumbapalayam. Statistical studies showed a significant correlation between the experimental variables and the quantity of $\mathrm{Zn}(\mathrm{II})$ ions adsorbed.

\section{Financial Support}

The authors have submitted their due acknowledgment to Defence Research \& Development Organisation (DRDO), New Delhi for the timely Financial Support $i+n$ execution of the research work. 


\section{References}

[1] H. M. Zwain, Comprehensive Study on Wastewater Treatment Using Low Cost Adsorbent, LAP Lambert Academic Publishing, Saarbrücken, Germany, 2012

[2] D. Balkose and H. Baltacioglu, "Adsorption of heavy metal cations from aqueous solutions by wool fibers," Journal of Chemical Technology and Biotechnology, vol. 54, no. 4, pp. 393-397, 1992.

[3] Jaafari, J., Yaghmaeian, K., 2019. Optimization of heavy metal biosorption onto freshwater algae (Chlorella coloniales) using response surface methodology (RSM). Chemosphere 217, 447-455

[4] Çelebi, H. \& Gök, O. Evaluation of lead adsorption kinetics and isotherms from aqueous solution using natural walnut shell. Int. J. Environ. Res. 11, 83-90 (2017).

[5] Benavente, V., Fullana, A. \& Berge, N. D. Life cycle analysis of hydrothermal carbonization of olive mill waste:comparison with current management approaches. J. Clean. Prod. 142, 2637-2648 (2017).

[6] Siddiqui, S. H. \& Ahmad, R. Pistachio Shell carbon (PSC) e an agricultural ads orbent for the removal of $\mathrm{Pb}(\mathrm{II})$ from aque ous solution. Groundw. Sustain. Dev. 4, 42-48 (2017).

[7] Ghorbani, F., Kamari, S., Zamani, S., Akbari, S. \& Salehi, M. Optimization and modeling of aqueous $\mathrm{Cr}(\mathrm{VI})$ adsorption onto activated carbon prepared from sugar beet bagasse agricultural waste by application of response surface methodology. Surf. Interfaces 18, $100444(2020$

[8] Feizi, M. \& Jalali, M. Removal of heavy metals from aqueous solutions using sunflower, potato, canola and walnut shell residues. J. Taiwan Inst. Chem. Eng. 54, 125-136 (2015)

[9] Achanai Buasri, Nattawut Chaiyut, Kessarin Tapang, Supparoek Jaroens in, and Sutheera Panphrom, Removal of $\mathrm{Cu} 2+$ from Aqueous Solution by Biosorption on Rice Straw - an Agricultural Waste Biomass, International Journal of Environmental Science and Development, Vol. 3, No. 1, Fe bruary 2012

[10] Efficient adsorption of Cr (VI) from aqueous solution on low cost adsorbent de veloped from Limonia acidissima (Wood apple) shell. Ads. Sci.\& Tech., 2010, 28 (6), 547-560..

[11] HakanDemiral, IlknurDemiral, FatmaTumsek, BelginKarabacakoglu, (2008), Adsorption of Chromium(VI) from aqueous solution by activated carbon derived from olive bagasse and applicability of different adsorption models, Chem. Eng. J., 144, 188-196. 
[12] M. Makeswari and Dr.T.Santhi, Use of Ricinus communis leaves as a low-cost adsorbent for removal of $\mathrm{Cu}(\mathrm{II})$ ions from aqueous solution, E-Journal of Chemistry 2009, 6(4), 1260-1266

[13] D Harikishore Kumar Reddy, K Seshaiah, AVR Reddy, M Madhava Rao, MC Wang, Biosorption of $\mathrm{Pb} 2+$ from aqueous solutions by Moringa oleifera bark: Equilibrium and kinetic studies, J. Hazard. Mater. 174 (2010) 831-838

[14] W Shaban Al Ramalli, A Abdella Dahmani, M Mohamed Abuein, A Amar Gleza, Biosorption of mercury from aqueous solutions by powdered leaves of castor tree (Ric inus communis L.), J. Hazard. Mater. 152 (2008) 955-959.

[15] Wasewar, K. L., Atif, M., Prasad, B. \& Mishra, I. M. Batch adsorption of zinc on tea factory waste. Desalination 244, 66-71 (2009).

[16] Hui Gao, Y unguo Liu, Guangming Zeng, Weihua Xu, Ting Li, Wenbin Xia, Characterization of $\mathrm{Cr}(\mathrm{VI})$ removal from aqueous solutions by a surplus agricultural waste-Rice straw, J. Hazard. Mater. 150 (2008) 446-452.

[17] Suresh Gupta, BV Babu, Utilization of waste product (tamarind seeds) for the removal of $\mathrm{Cr}(\mathrm{VI})$ from aqueous solutions: Equilibrium, kinetics, and regeneration studies, $\mathrm{J}$. Environ. Manage. 90 (2009) 3013-3022.

[18] Silke Schiewer, Ankit Balaria, Biosorption of $\mathrm{Pb} 2+$ by original and protonated citrus peels: Equilibrium, kinetics and mechanis ms, Chem. Eng. J. 146 (2009) 211-219.

[19] B Stephen Inbaraj, N Sulochana, Mercury adsorption on a carbon sorbent derived from fruit shell of Terminalia catappa, J. Hazard. Mater. 133 (2006) 283-290

[20] Han JS, Rowell JS. Chemical composition of agro-based fibers, paper and composites from agro-based resources. Boca Raton: CRC Press,1996; pp. 83-134

[21] Nemr A.E., J. Haz. Mat.,161,(2009), 132- 141.

[22] Muhammad Riaz, RaziyaNadeem, Muhammad AsifHanif, Tariq Mehmood Ansari, Khalil-ur-Rehman, J. Haz. Mat., 161 (2008), 88-94.

[23] Mehmet EminArgun, SukruDursun, CelalettinOzdemir, Mustafa Karatas, J. Haz. Mat., 141, (2007), 77-85

[24] Nameni. M., AlaviMoghadam. M. R., Arami. M., Inter.J. Env. Sci.\& Tech., 5,(2008), $161-168$

[25] Hanim Awab; Thanalechumi Paramalinggam, J. of Fund. Sci., 2012, 7(2), 113-119. 
[26] Kaustubha Mohanty, Mousam Jha, BC Meikap, MN Biswas, Removal of chromium (VI) from dilute aqueous solutions by activated carbon developed from Terminalia arjuna nuts activated with zinc chloride, Chem. Eng. Sci. 60 (2005) 3049-3059.

[27] C. Namasivayam, M.V. Sureshkumar, Removal of chromium(VI) from water and wastewater using surfactant modified coconut coir pith as a bios orbent,

Bio resource. Technol. 99 (2008) 2218-2222.

[28] D. Nityanandi, C.V. Subbhuraam, Kinetics and thermodynamic of adsorption of chromium(VI) from aqueous solution using puresorbe. J. Hazard. Mater. 170 (2009) 876882.

[29] Runping Han, Jinghua Zhang, Weihua Zou, Jie Shi, Hongmin Liu, Equilibrium bios orption is otherm for lead ion on chaff, J. Hazard. Mater. 125 (2005) 266-271.

[30] HP Boehm, Some aspects of the surface chemistry of carbon blacks and other carbons, Carbon. 32 (1994) 759-769.

[31] Yuh-Shan Ho, Review of second-order models for adsorption systems, J. Hazard. Mater. 136 (2006) 681-689.

[32] Efficient adsorption of Cr (VI) from aqueous solution on low cost adsorbent developed from Limonia acidissima (Wood apple) shell. Ads. Sci.\& Tech., 2010, 28 (6), 547-560.

[33] KP Shubha, C Raji, TS Anirudhan, Immobilization of heavy metals from aqueous solutions using polyacrylamide grafted hydrous Tin(IV) oxide gel having carboxylate functional groups, Water Res. 35 (2001) 300-310.

[34] Yuh-Shan Ho, Chung-Chi Wang, Sorption equilibrium of mercury onto ground-up tree fern, J. Hazard. Mater. 156 (2008) 398-404

[35] Alka Shukla, Yu-Hui Zhang, P Dubey, JL Margrave, S Shyam Shukla, The role of sawdust in the removal of unwanted materials from water, J. Hazard. Mater. 95 (2002) 137-152.

[36] Suresh Gupta, BV Babu, Utilization of waste product (tamarind seeds) for the removal of $\mathrm{Cr}(\mathrm{VI})$ from aqueous solutions: Equilibrium, kinetics, and regeneration studies, J. Environ. Manage. 90 (2009) 3013-3022 
Figures
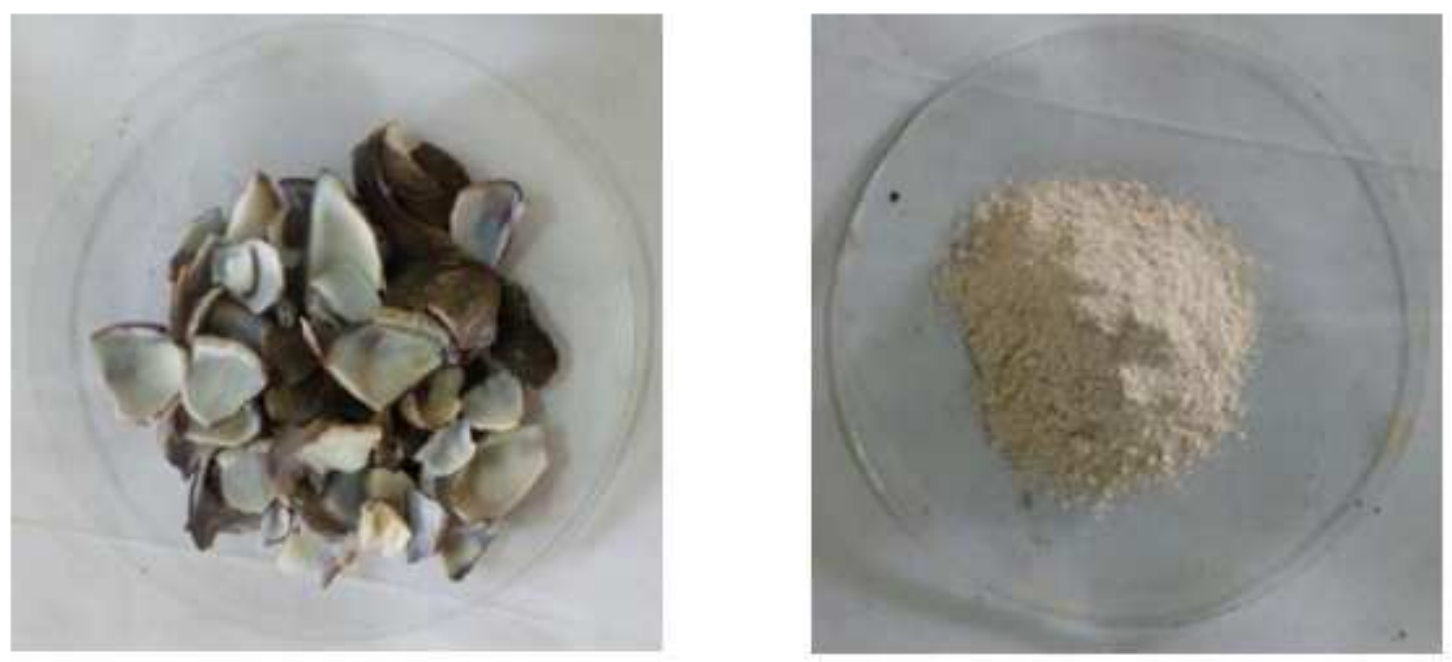

Figure 1

a Untreated mollusc shell b TMSP
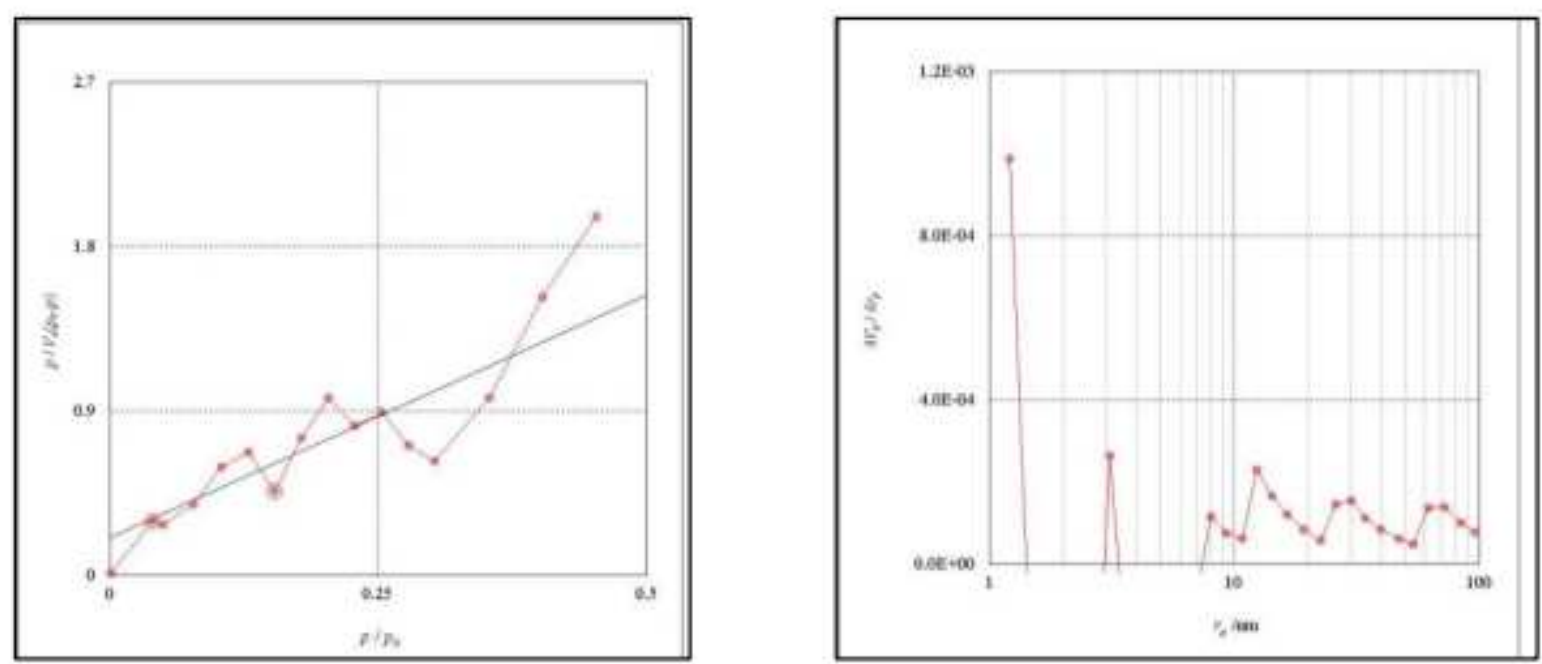

Figure 2

a BET plot for TMSP b BJH plot for TMSP 

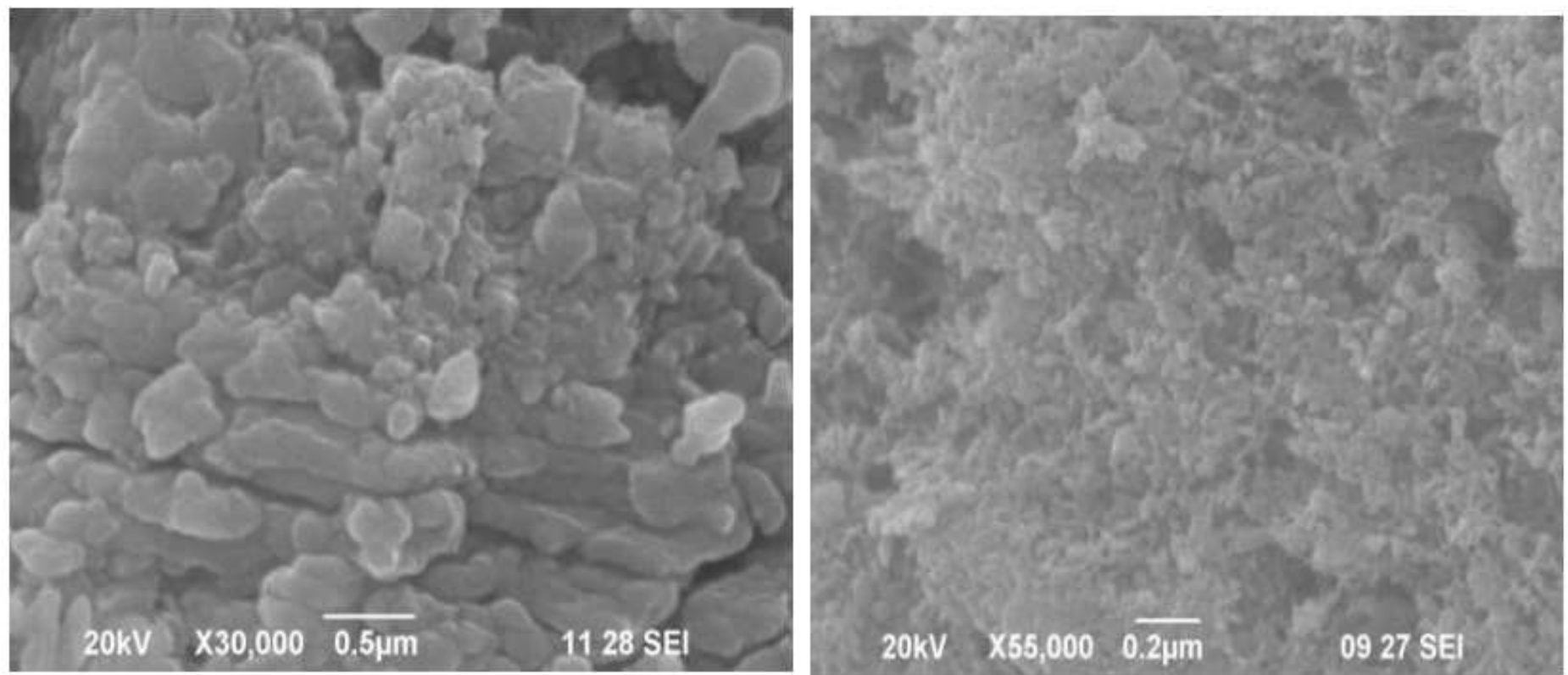

Figure 3

a: Unloaded TMSP- SEM b: Zn(II) loaded TMSP- SEM
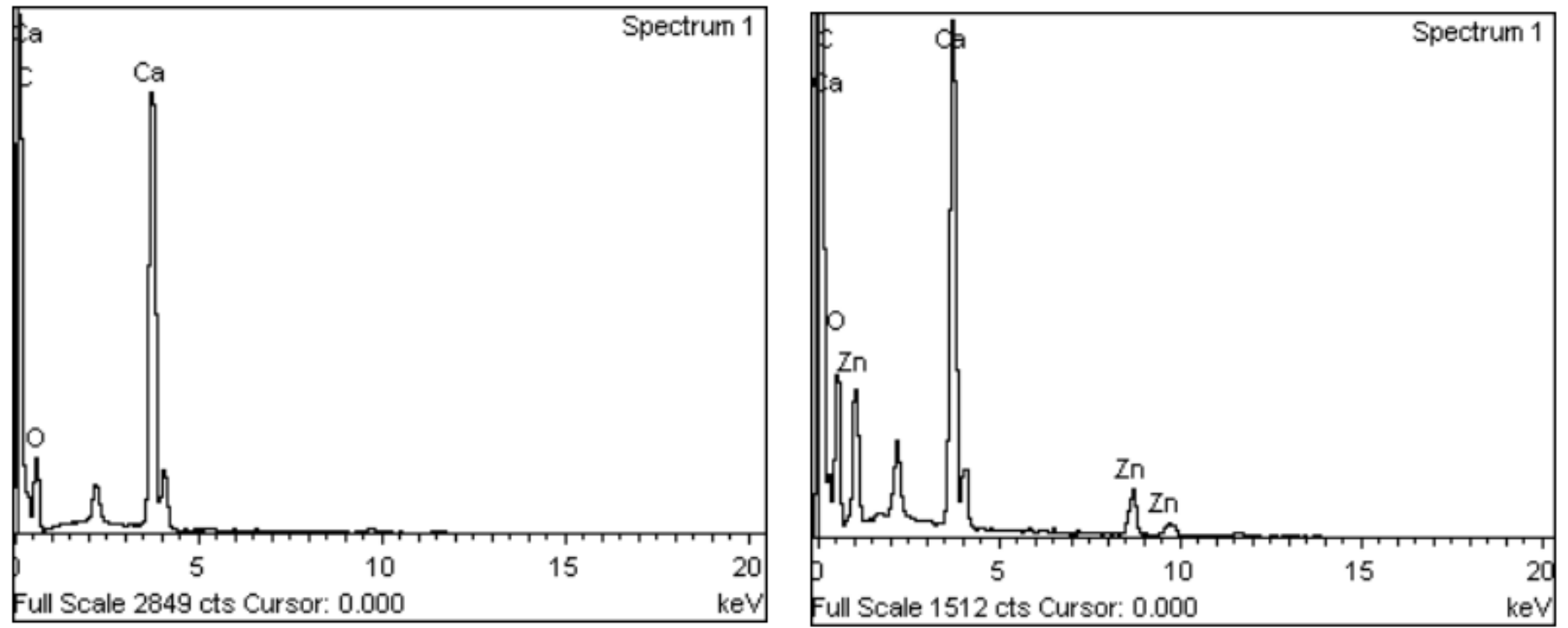

Figure 4

a Unloaded TMSP- EDAX spectra b Zn(II) loaded TMSP- EDAX spectra 


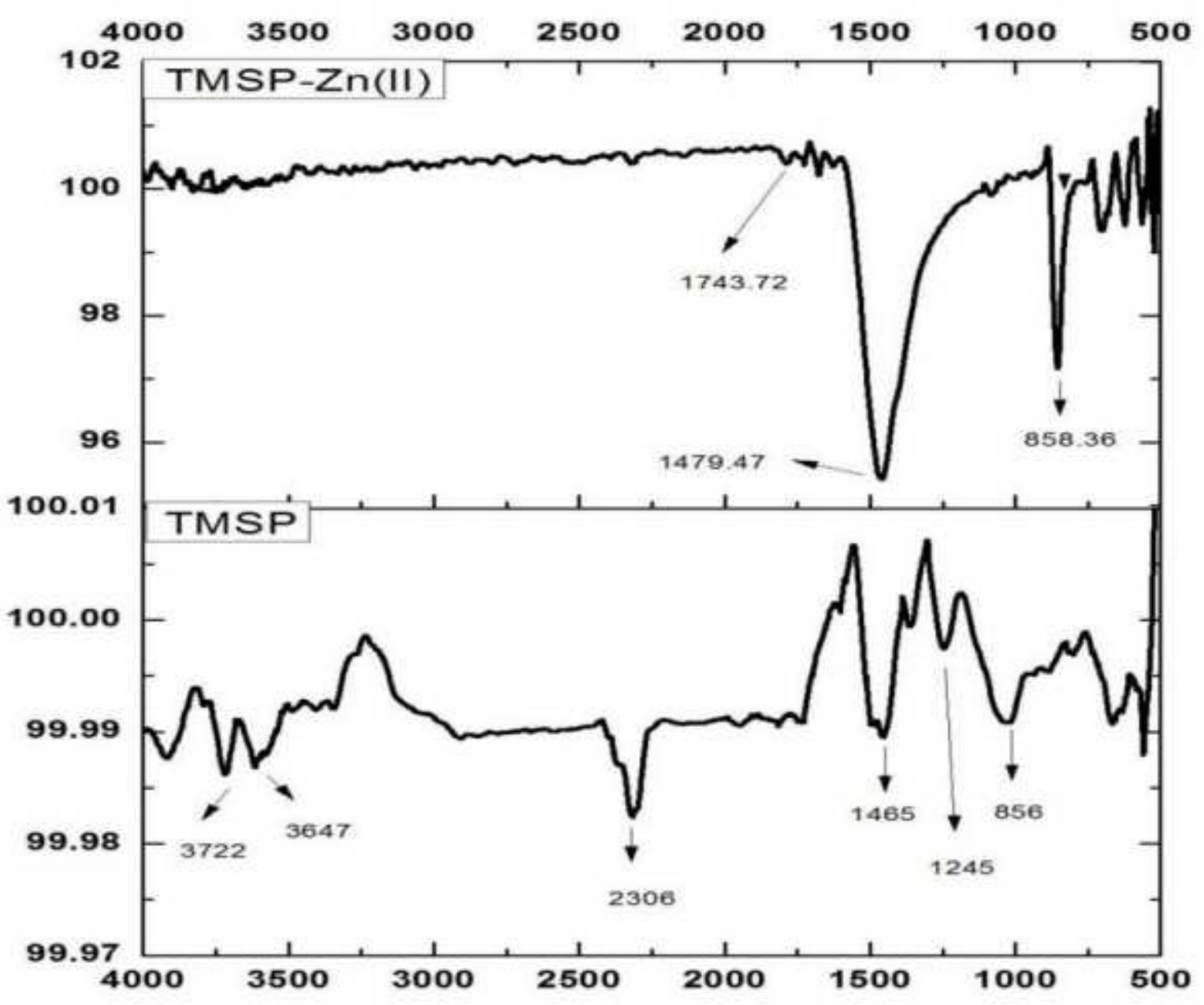

Figure 5

IR spectra of Unloaded and Zn(II) loaded TMSP 


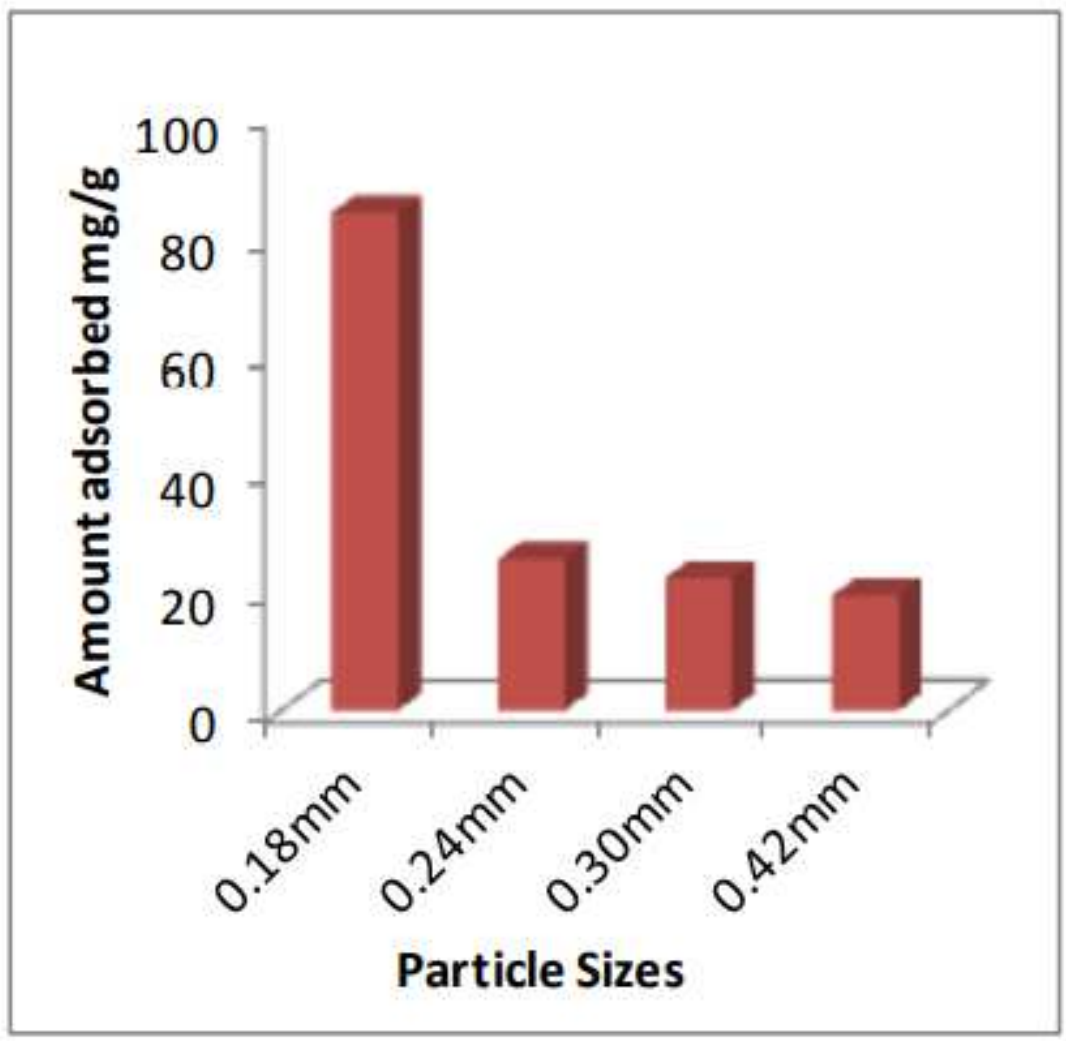

Figure 6

Particle Size-TMSP

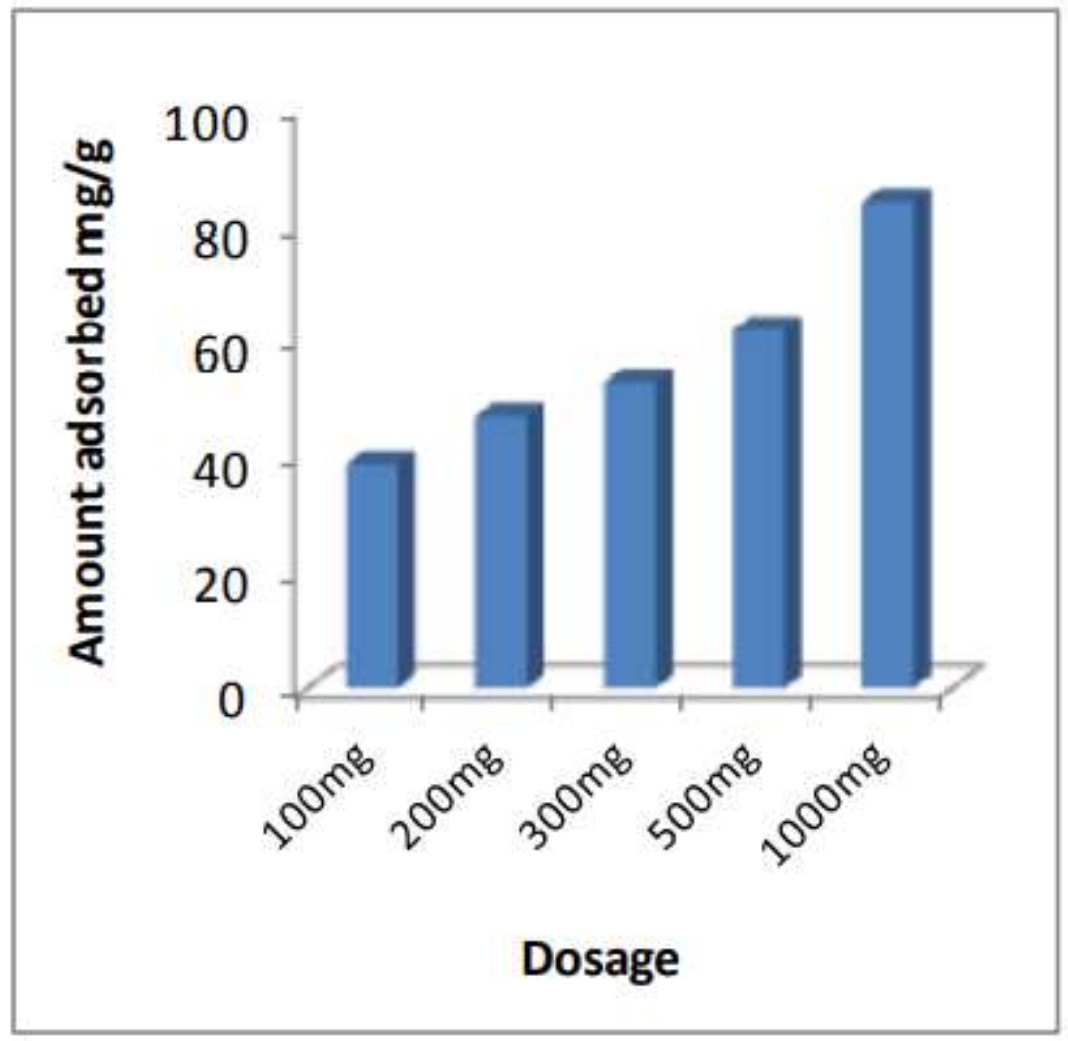


Figure 7

Dosages-TMSP

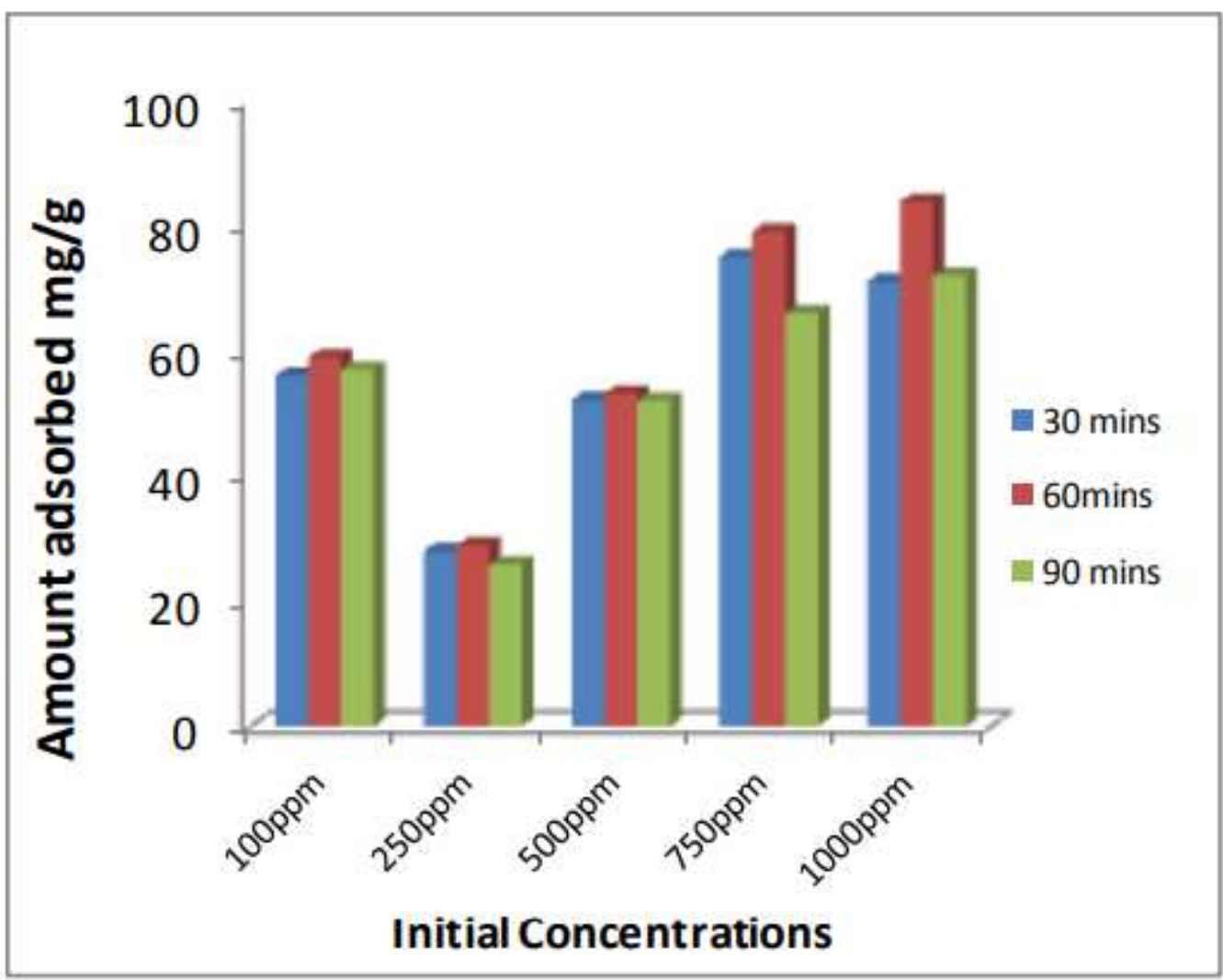

Figure 8

Initial Concentrations 


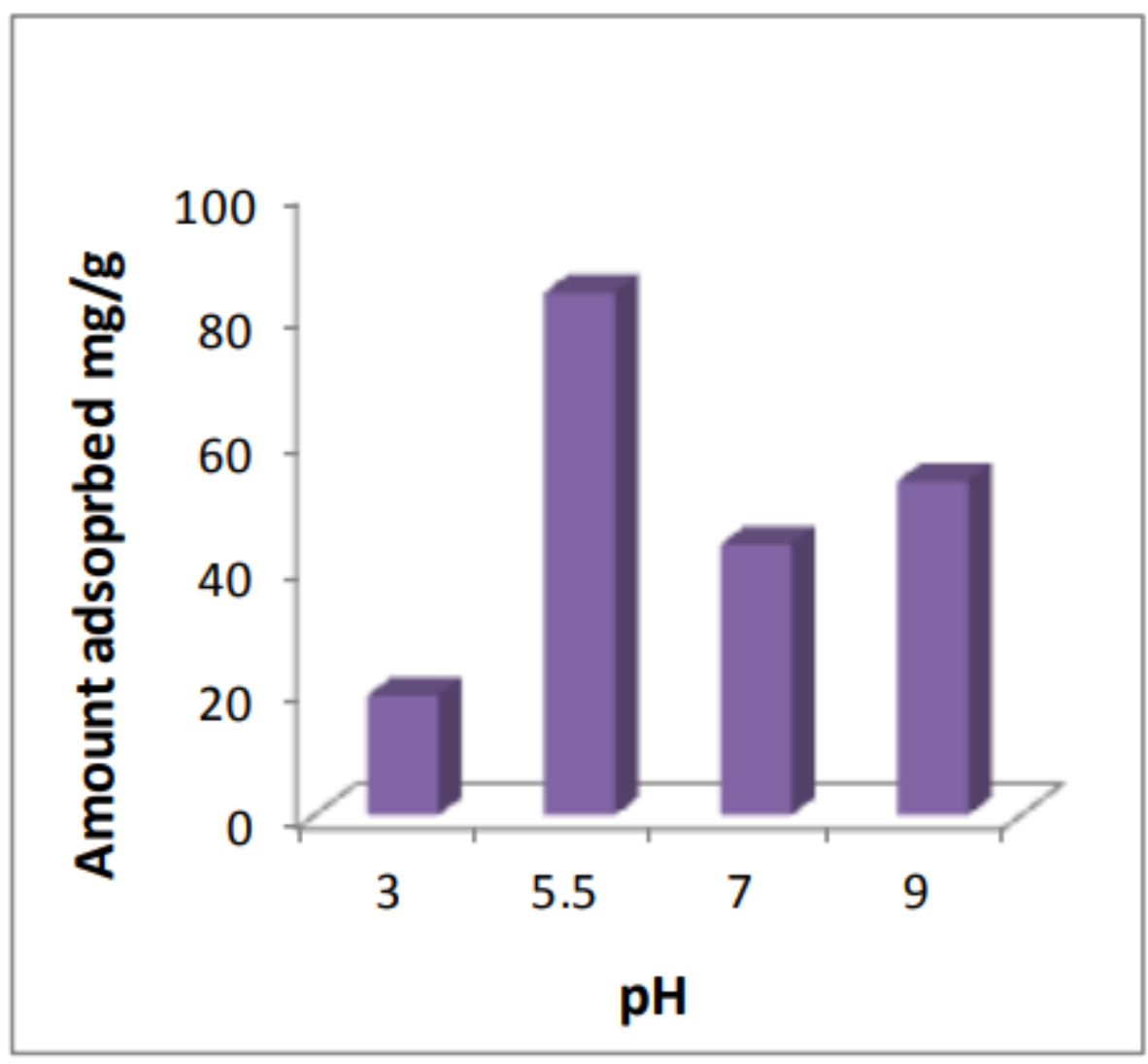

Figure 9

Effect of $\mathrm{pH}$

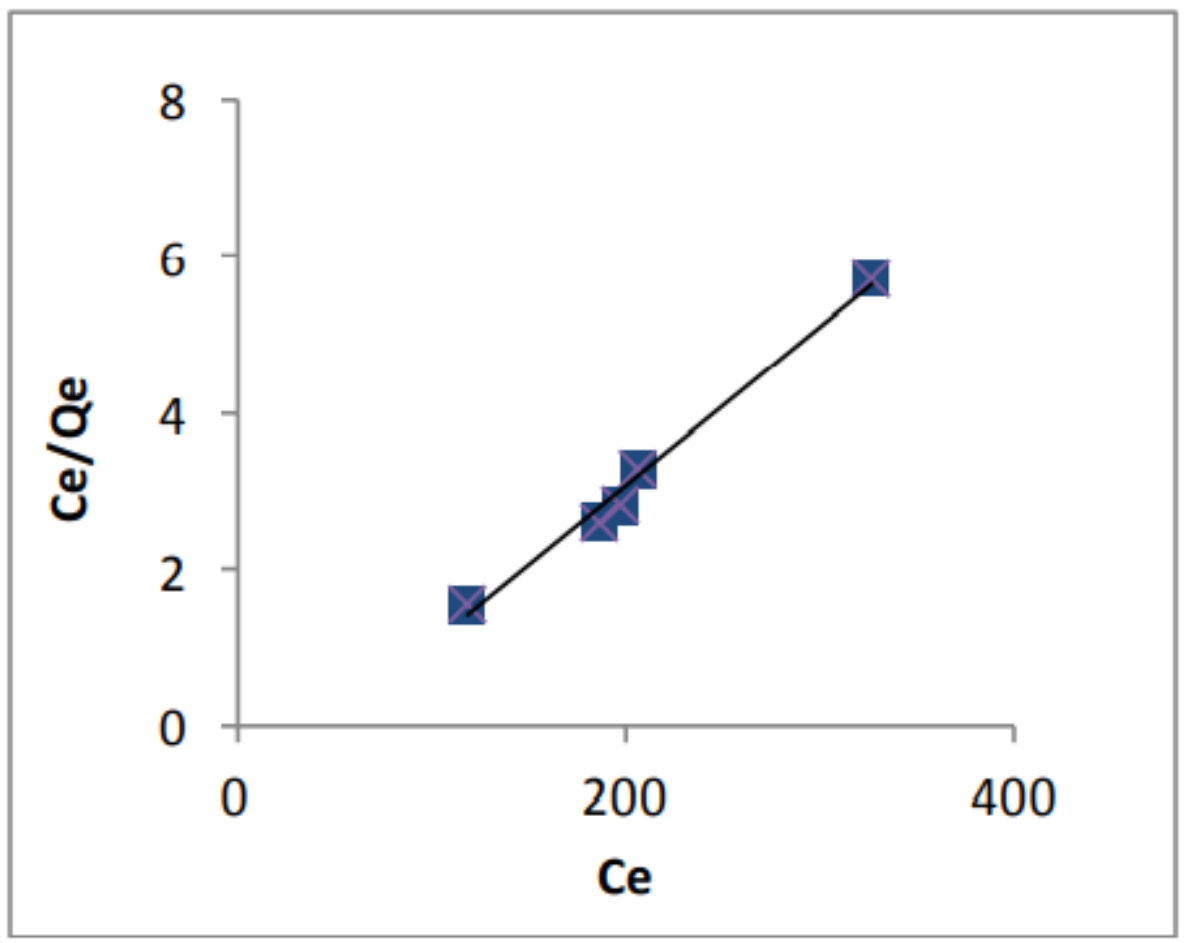

Figure 10 


\section{Langmuir Isotherm}

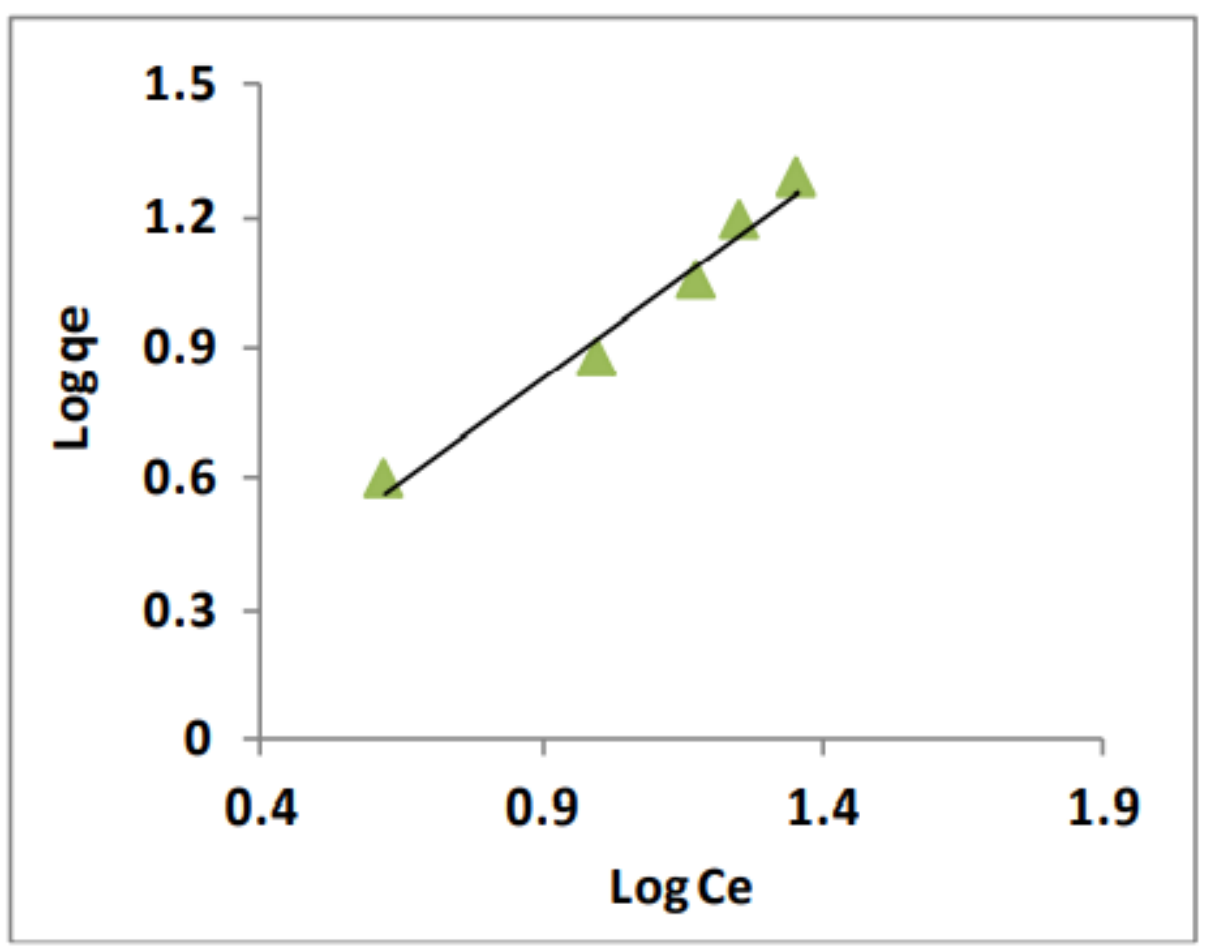

\section{Figure 11}

Freundlich Isotherm

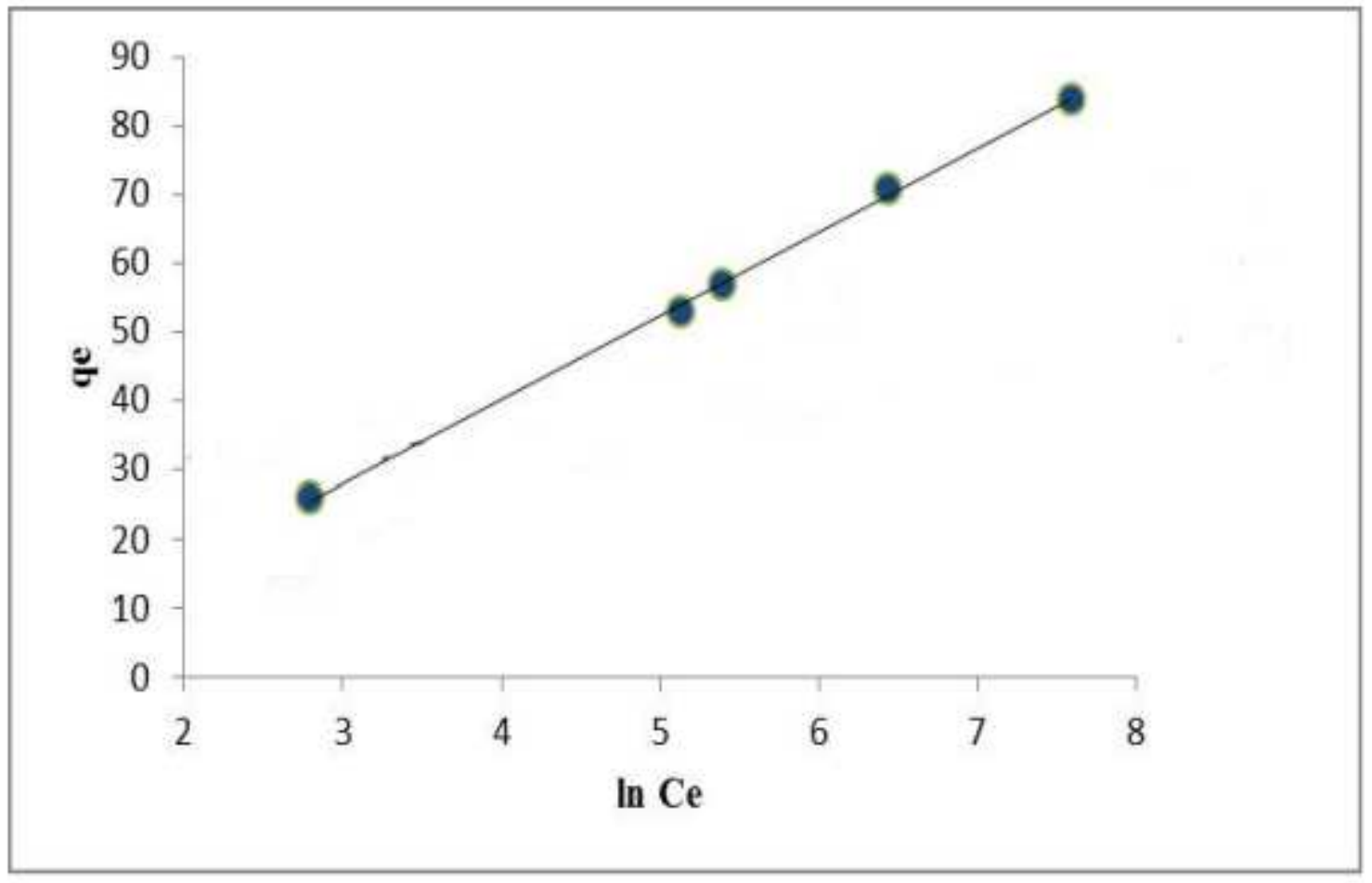

Figure 12 
Tempkin Isotherm Model

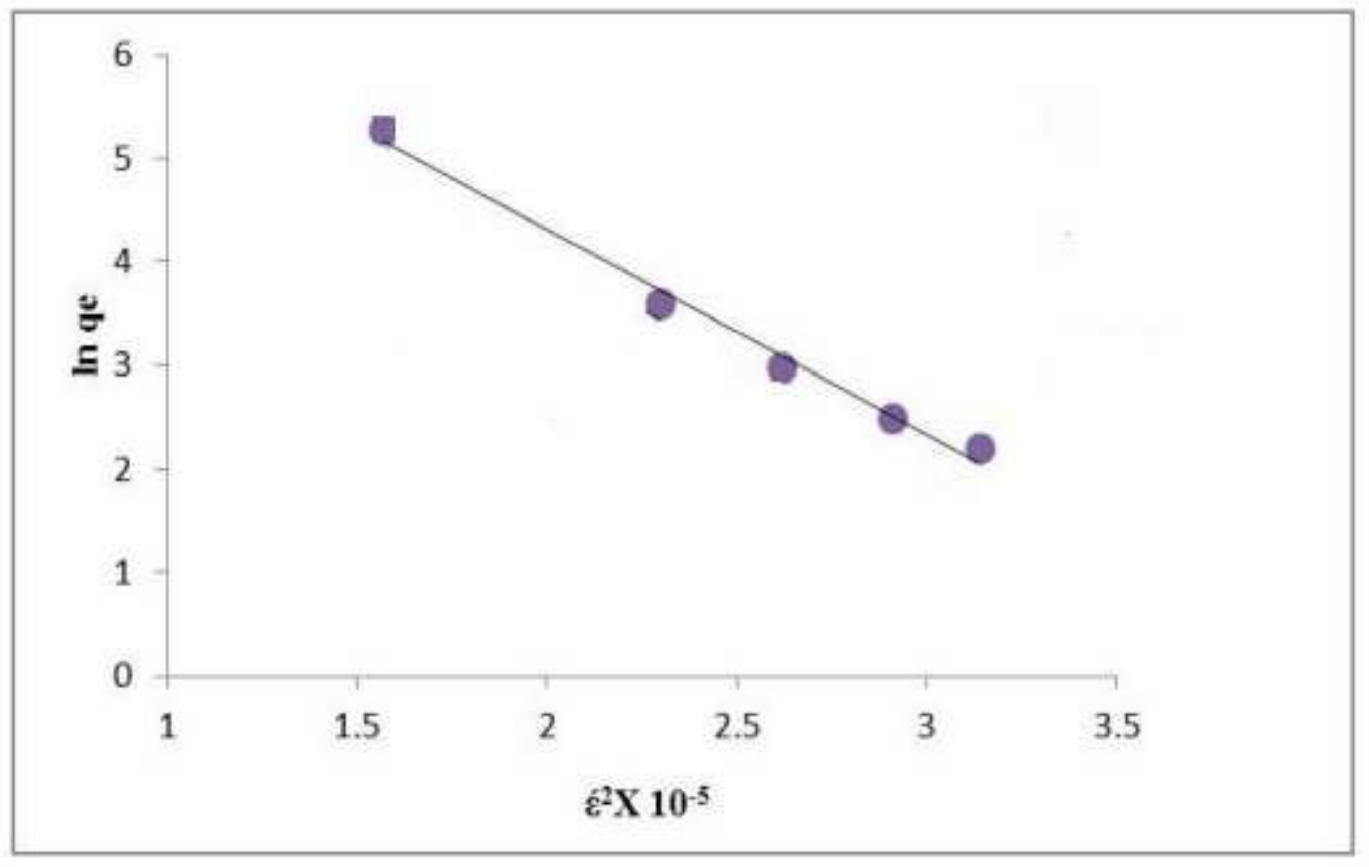

Figure 13

Dubinin-Kaganer-Radushkevich Isotherm Model

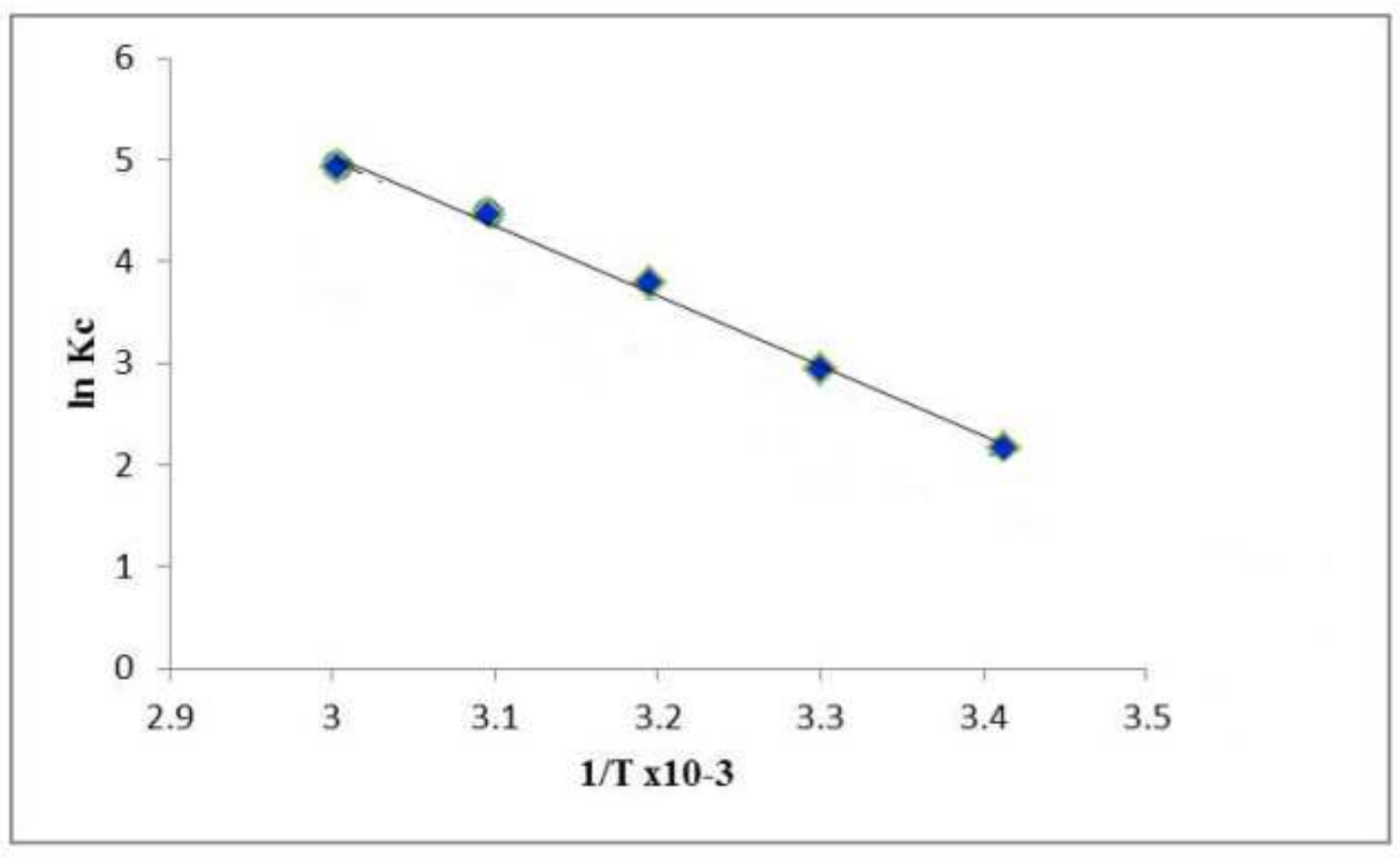

Figure 14

Vant Hoff's plot 


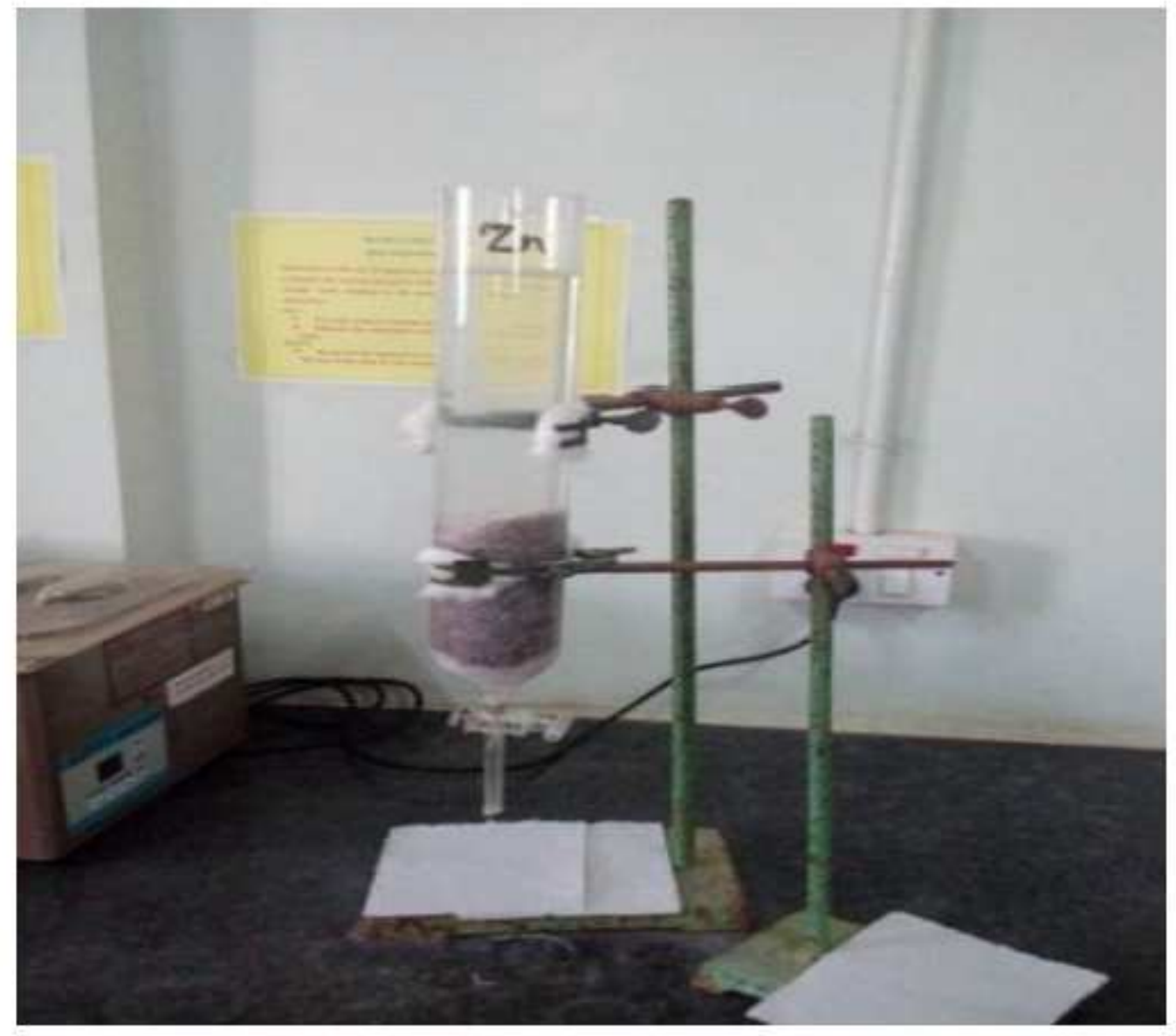

Figure 15

Zn(II)- TMSP 


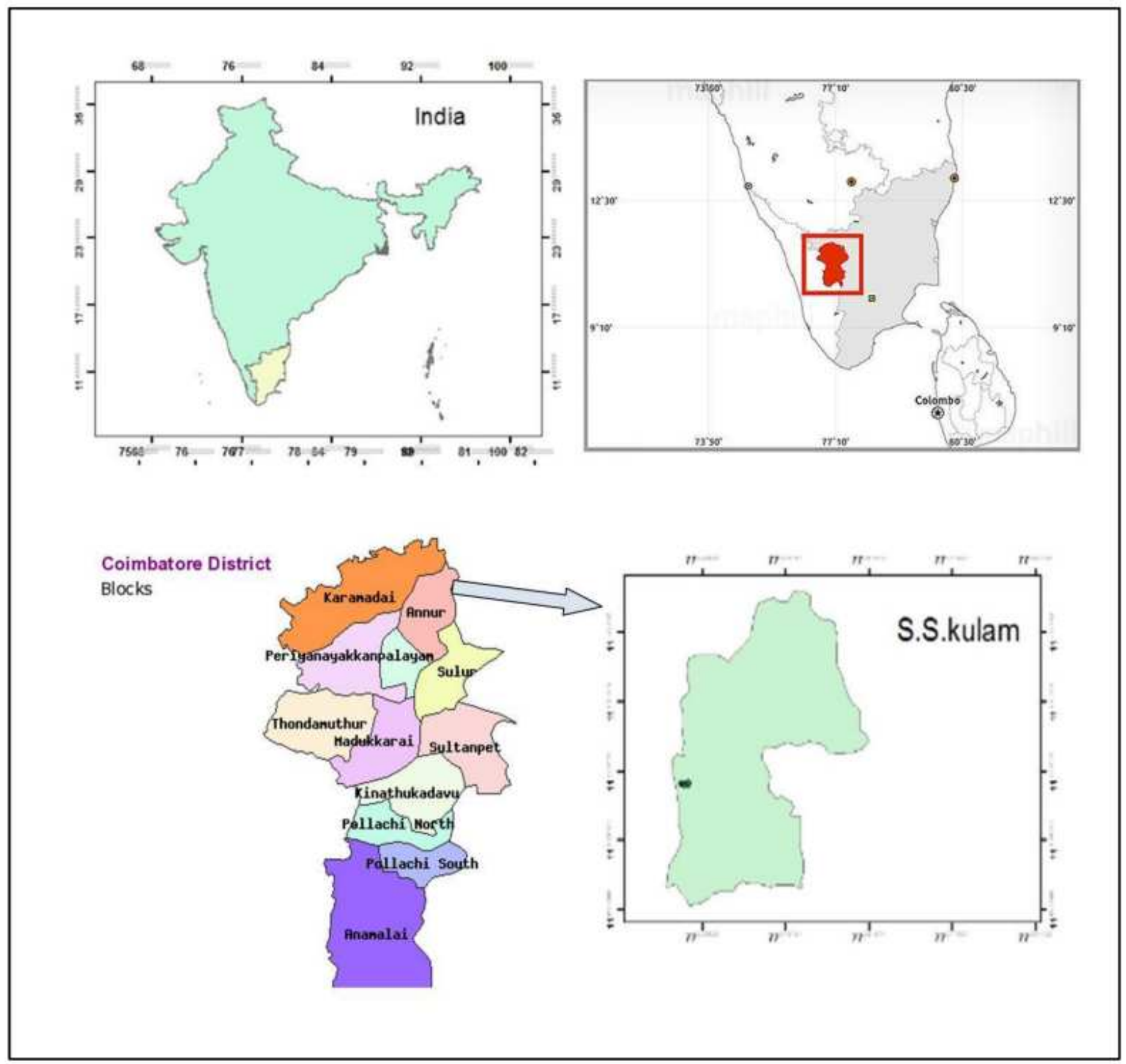

Figure 16

GIS Mapping of Kurumbapalayam Area 

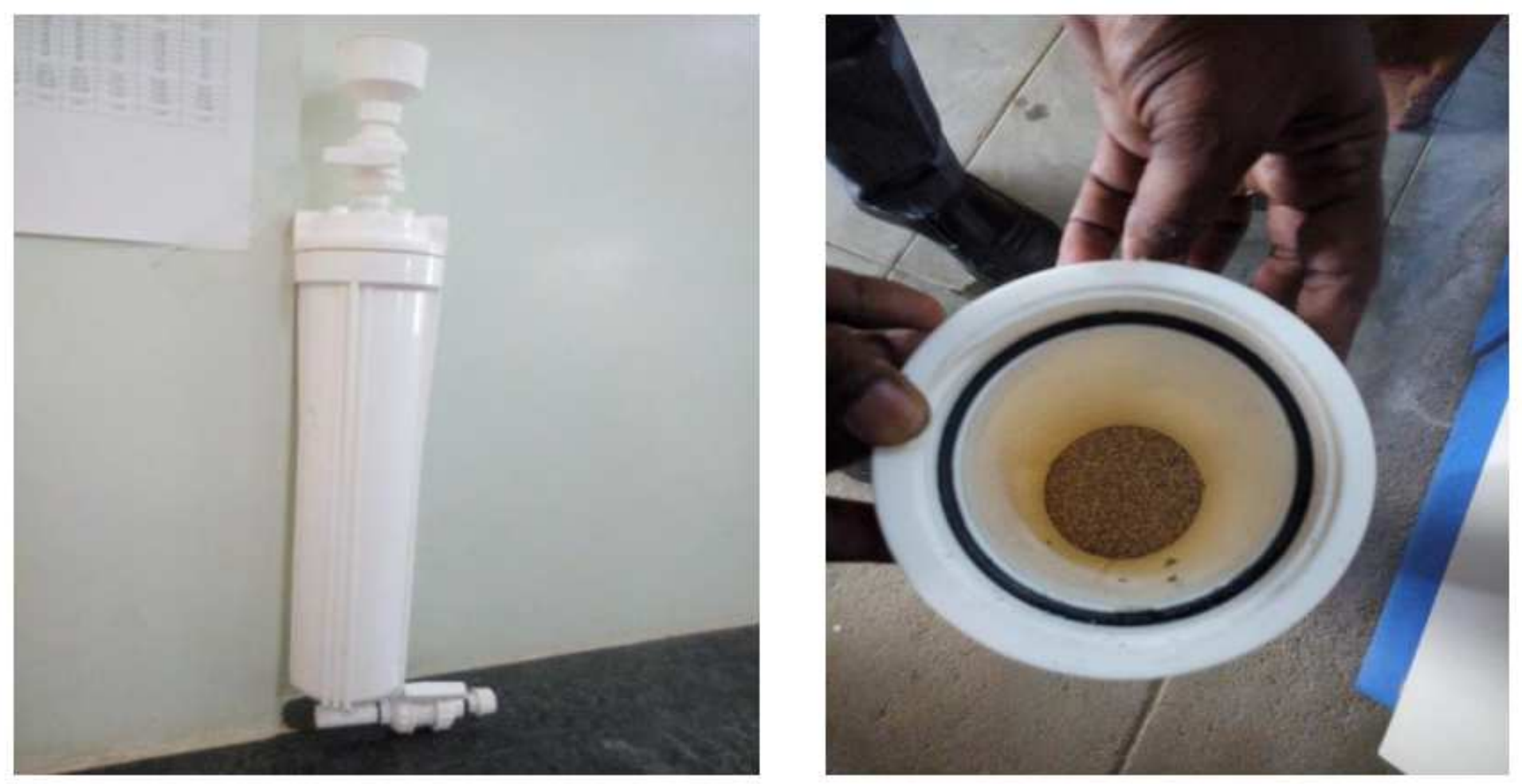

Figure 17

FRP Column

\section{Supplementary Files}

This is a list of supplementary files associated with this preprint. Click to download.

- Tables.pdf

- Graphicalabstract.pdf 